\title{
Usage Patterns of Web-Based Stroke Calculators in Clinical Decision Support: Retrospective Analysis
}

Benjamin Kummer ${ }^{1,2}$, MD; Lubaina Shakir ${ }^{3}$, MSc; Rachel Kwon ${ }^{4}$, MD; Joseph Habboushe ${ }^{3,5}$, MD, MBA; Nathalie Jetté $^{1,6}$, MD, MSc

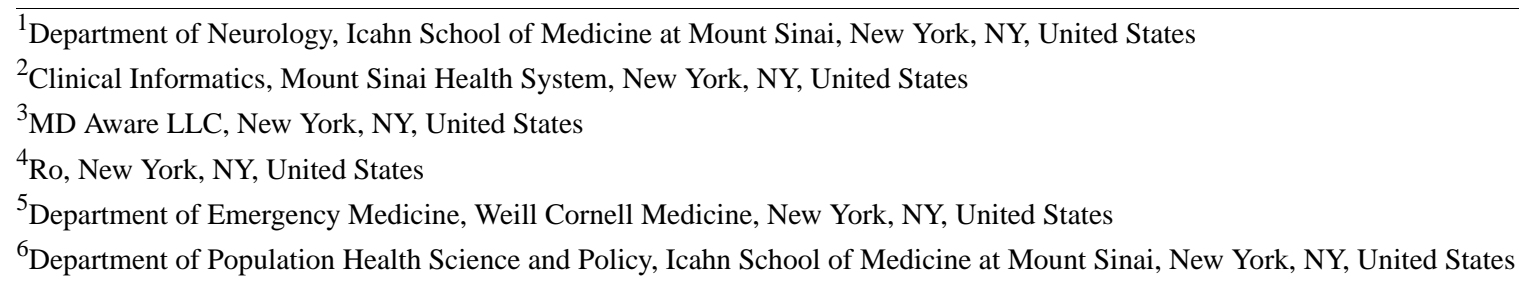

Corresponding Author:

Benjamin Kummer, MD

Department of Neurology

Icahn School of Medicine at Mount Sinai

One Gustave Levy Pl

Box 1137

New York, NY, 10029

United States

Phone: 12122415050

Email: benjamin.kummer@mountsinai.org

\section{Abstract}

Background: Clinical scores are frequently used in the diagnosis and management of stroke. While medical calculators are increasingly important support tools for clinical decisions, the uptake and use of common medical calculators for stroke remain poorly characterized.

Objective: We aimed to describe use patterns in frequently used stroke-related medical calculators for clinical decisions from a web-based support system.

Methods: We conducted a retrospective study of calculators from MDCalc, a web-based and mobile app-based medical calculator platform based in the United States. We analyzed metadata tags from MDCalc's calculator use data to identify all calculators related to stroke. Using relative page views as a measure of calculator use, we determined the 5 most frequently used stroke-related calculators between January 2016 and December 2018. For all 5 calculators, we determined cumulative and quarterly use, mode of access (eg, app or web browser), and both US and international distributions of use. We compared cumulative use in the 2016-2018 period with use from January 2011 to December 2015.

Results: Over the study period, we identified 454 MDCalc calculators, of which 48 (10.6\%) were related to stroke. Of these, the 5 most frequently used calculators were the $\mathrm{CHA}_{2} \mathrm{DS}_{2}$-VASc score for atrial fibrillation stroke risk calculator (5.5\% of total and $32 \%$ of stroke-related page views), the Mean Arterial Pressure calculator $(2.4 \%$ of total and $14.0 \%$ of stroke-related page views), the HAS-BLED score for major bleeding risk (1.9\% of total and $11.4 \%$ of stroke-related page views), the National Institutes of Health Stroke Scale (NIHSS) score calculator (1.7\% of total and $10.1 \%$ of stroke-related page views), and the $\mathrm{CHADS}_{2}$ score for atrial fibrillation stroke risk calculator (1.4\% of total and $8.1 \%$ of stroke-related page views). Web browser was the most common mode of access, accounting for $82.7 \%-91.2 \%$ of individual stroke calculator page views. Access originated most frequently from the most populated regions within the United States. Internationally, use originated mostly from English-language countries. The NIHSS score calculator demonstrated the greatest increase in page views (238.1\% increase) between the first and last quarters of the study period.

Conclusions: The most frequently used stroke calculators were the $\mathrm{CHA}_{2} \mathrm{DS}_{2}$-VASc, Mean Arterial Pressure, HAS-BLED, NIHSS, and $\mathrm{CHADS}_{2}$. These were mainly accessed by web browser, from English-speaking countries, and from highly populated 
areas. Further studies should investigate barriers to stroke calculator adoption and the effect of calculator use on the application of best practices in cerebrovascular disease.

(JMIR Med Inform 2021;9(8):e28266) doi: 10.2196/28266

\section{KEYWORDS}

medical informatics; clinical informatics; mhealth; digital health; cerebrovascular disease; medical calculators; health information; health information technology; information technology; economic health; clinical health; electronic health records

\section{Introduction}

Since the introduction of the Health Information Technology for Economic and Clinical Health Act in 2009, hospital systems in the United States have seen a five-fold increase in electronic health record (EHR) system adoptions [1,2]. These increases in EHR adoption have been accompanied by an upsurge in the amount of clinical data contained in EHRs. Providers' increasingly challenging task of managing this growing amount of information may result in cognitive burdening [3]. Moreover, the manner in which many EHRs display large amounts of clinical information may not support optimal cognitive reasoning [4]. Providers that use EHRs may therefore experience a number of unwanted adverse effects, including reductions in situational awareness, increases in mental workload, and reduced cognitive performance [5].

Clinical decision support (CDS) systems endeavor to enhance health care delivery by providing clinician-facing and patient-facing information that can improve decision-making at key steps in the workflow [6]. CDS systems are common in modern EHRs and range from passive banners to modal alerting systems for clinical conditions and adverse drug interactions $[7,8]$. Given that they are capable of delivering variably complex and tailored clinical content at the point of care [9], CDS systems are also well-suited for reducing cognitive overload. Medical calculators are specialized CDS instruments that incorporate user-entered clinical parameters to compute the discrete output of various types of functions $[6,10]$, including physiological equations, risk stratification scores, and disease-quantifying or disability-quantifying scales. While medical calculators are increasingly prevalent in the growing armamentarium of CDS solutions available to providers, few studies have investigated their use patterns and barriers to adoption [5,10,11].

Stroke is a leading cause of disability and mortality worldwide, imposing a heavy economic and public health burden [12,13]. Several clinical scoring systems that draw on clinical, demographic, and laboratory parameters to predict risk, determine disease severity, or grade disability are widely available for the evaluation and management of stroke [14-28]. While medical calculators lend themselves naturally to such use cases, there is a lack of studies describing the current state of medical calculator use in stroke and cerebrovascular disease. Considering this and the need to better understand the adoption and use of medical calculators, we sought to study the use patterns of frequently used stroke calculators from a widely used web platform.

\section{Methods}

We conducted a retrospective, descriptive study of medical calculators published by MDCalc (MD Aware LLC, New York, NY, USA), a free, web-based and mobile app-based CDS platform that is used by over $65 \%$ of US-based physicians monthly and millions of clinicians worldwide [29]. MDCalc's CDS tools consist of medical score calculator forms for over 200 clinical conditions that allow users to input clinical variables and visualize clinical score outputs, along with an interpretation of the output and an appraisal of the available evidence supporting the use for each score (Multimedia Appendix 1) $[6,29]$.

We used MDCalc's analytics platform to identify all calculators that were accessed between January 1, 2016 and December 31, 2018. We extracted calculator names; number of cumulative, nonunique page views; mode of access (eg, mobile app or web page); page view ranks; and calculator metadata, including launch dates and structured disease area categories (ie, "tags"). Page view ranks were assigned for each calculator based on total page views over the study period, with the lowest rank corresponding to the highest number of page views. Each calculator's cumulative page views were expressed relative to total cumulative page views for the entire MDCalc platform over the study period.

We defined calculators related to stroke as any calculator that contained 1 or more stroke-related tag (ie, "ischemic stroke," "transient ischemic attack," "intracerebral hemorrhage," or "subarachnoid hemorrhage"). For the 5 calculators with the highest relative page views over the study period, we determined quarterly page views, page views stratified by mode of access (eg, web page, iOS mobile app, or Android mobile app), country, and US state. For each calculator, we additionally determined page views relative to all stroke-related calculators and calculated the rate of increase in relative page views between the first and last quarter of the study period. To describe the evolution in stroke-related calculator use and rankings in the 5 years prior to the start of the study period, we determined relative page views and ranks for the same 5 calculators between January 1, 2011 and December 31, 2015. We then compared these measurements to those for the 2016-2018 study period. We only included calculators that were published by MDCalc.

\section{Results}

Between January 1, 2016 and December 31, 2018, we identified 454 MDCalc calculators, of which 48 (10.6\%) were related to stroke. By cumulative page view, the 5 most highly ranked stroke calculators were the $\mathrm{CHA}_{2} \mathrm{DS}_{2}$-VASc (congestive heart 
failure, hypertension, 75 years of age and older, diabetes mellitus, previous stroke or transient ischemic attack, vascular disease, 65 to 74 years of age, female) score for atrial fibrillation stroke risk calculator $(5.5 \%$ of total MDCalc and $32 \%$ of stroke-related page views), the Mean Arterial Pressure (MAP) calculator $(2.4 \%$ of total MDCalc and $14 \%$ of stroke-related page views), the HAS-BLED (hypertension, abnormal renal/liver function, stroke, bleeding history or predisposition, labile international normalized ratio, elderly, drugs/alcohol concomitantly) score for major bleeding risk calculator (1.9\% of total MDCalc and $11.4 \%$ of stroke-related page views), the National Institutes of Health Stroke Scale (NIHSS) score calculator (1.7\% of total MDCalc and $10.1 \%$ of stroke-related page views), and the $\mathrm{CHADS}_{2}$ (congestive heart failure, hypertension, 75 years of age or older, diabetes mellitus, and previous stroke or transient ischemic attack) score for atrial fibrillation stroke risk calculator (1.4\% of total MDCalc and $8.1 \%$ of stroke-related page views; Table 1$)$.

Table 1. Relative page views and ranks of the 5 most frequently used MDCalc stroke calculators, 2011-2018.

\begin{tabular}{|c|c|c|c|c|c|c|c|c|}
\hline & & & $2011-2015^{\mathrm{a}}$ & & & $2016-2018^{b}$ & & \\
\hline Calculator & Description $^{\mathrm{c}}$ & Launch date & $\begin{array}{l}\text { Proportion of } \\
\text { all calculator } \\
\text { page views, } \\
\% \text { d,e }\end{array}$ & $\begin{array}{l}\text { Proportion of } \\
\text { stroke calcula- } \\
\text { tor page views, } \\
\% \mathrm{~d}, \mathrm{f}\end{array}$ & Rank $^{\mathrm{g}}$ & $\begin{array}{l}\text { Proportion of } \\
\text { all calculator } \\
\text { page views, } \\
\% \text { d,e }\end{array}$ & $\begin{array}{l}\text { Proportion of } \\
\text { stroke calcula- } \\
\text { tor page views, } \\
\% \text { h }\end{array}$ & $\operatorname{Rank}^{\mathrm{g}}$ \\
\hline $\mathrm{CHA}_{2} \mathrm{DS}_{2}-\mathrm{VASc}^{\mathrm{i}}$ & $\begin{array}{l}\text { Calculates stroke } \\
\text { risk for patients } \\
\text { with atrial fibrilla- } \\
\text { tion, possibly bet- } \\
\text { ter than the } \\
\text { CHADS }_{2}{ }^{j} \text { score }\end{array}$ & April 1, 2011 & 4.9 & 38.7 & 2 & 5.5 & 32 & 2 \\
\hline $\mathrm{MAP}^{\mathrm{k}}$ & $\begin{array}{l}\text { Calculates mean } \\
\text { arterial pressure }\end{array}$ & January 1, 2009 & 1.1 & 8.6 & 31 & 2.4 & 14 & 7 \\
\hline HAS-BLED ${ }^{1}$ & $\begin{array}{l}\text { Estimates risk of } \\
\text { major bleeding for } \\
\text { patients on antico- } \\
\text { agulation to assess } \\
\text { risk-benefit in atri- } \\
\text { al fibrillation care }\end{array}$ & April 1, 2011 & 2.2 & 17.4 & 12 & 1.9 & 11.4 & 9 \\
\hline NIHSS $^{\mathrm{m}}$ & $\begin{array}{l}\text { Calculates the } \\
\mathrm{NIH}^{\mathrm{n}} \text { Stroke Scale } \\
\text { for quantifying } \\
\text { stroke severity }\end{array}$ & January 1, 2009 & 1.0 & 7.7 & 33 & 1.7 & 10.1 & 15 \\
\hline $\mathrm{CHADS}_{2}$ & $\begin{array}{l}\text { Estimates stroke } \\
\text { risk in patients } \\
\text { with atrial fibrilla- } \\
\text { tion }\end{array}$ & January 1, 2009 & 2.9 & 22.6 & 7 & 1.4 & 8.1 & 22 \\
\hline
\end{tabular}

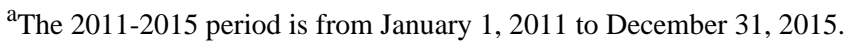

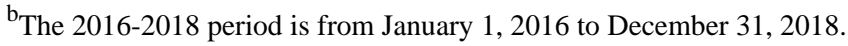

${ }^{\mathrm{c}}$ Descriptions are as appears on each MDCalc calculator webpage.

${ }^{\mathrm{d}}$ All page views exclude Android/iOS MDCalc app page views.

${ }^{\mathrm{e}}$ Percentage is relative to page views for all MDCalc calculators available during specified period.

${ }^{\mathrm{f}}$ Percentage is relative to page views for 22 stroke-related calculators available during specified period.

${ }^{g}$ Rank is assigned according to cumulative, nonunique MDCalc page views relative to all available MDCalc calculator page views for each specified period; lowest rank corresponds to the highest proportion of page views.

${ }^{\mathrm{h}}$ Percentage is relative to page views for 48 stroke-related calculators available during specified period.

${ }^{\mathrm{i}} \mathrm{CHA}_{2} \mathrm{DS}_{2}$-VASc: congestive heart failure, hypertension, 75 years of age and older, diabetes mellitus, previous stroke or transient ischemic attack, vascular disease, 65 to 74 years of age, female.

${ }^{\mathrm{j}} \mathrm{CHADS}_{2}$ : congestive heart failure, hypertension, 75 years of age or older, diabetes mellitus, and previous stroke or transient ischemic attack.

${ }^{\mathrm{k}} \mathrm{MAP}:$ mean arterial pressure.

${ }^{1}$ HAS-BLED: hypertension, abnormal renal/liver function, stroke, bleeding history or predisposition, labile international normalized ratio, elderly, drugs/alcohol concomitantly.

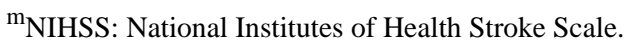

${ }^{\mathrm{n}} \mathrm{NIH}$ : National Institutes of Health. 
Native English-language countries accounted for the highest proportion of page views for all calculators. Among individual countries, the United States, followed by the United Kingdom, accounted for the highest proportion of page views for all calculators except for the $\mathrm{CHADS}_{2}$ score, for which Canada accounted for the second-highest proportion of page views. Within the United States, the states of California, Texas, New York, Pennsylvania, and Florida accounted for the highest proportion of page views for all calculators except the MAP score, for which Washington, California, Oregon, Texas, and
New York accounted for the greatest share. Among individual states, the highest proportion of page views originated from California for the $\mathrm{CHA}_{2} \mathrm{DS}_{2}$-VASc, NIHSS, and $\mathrm{CHADS}_{2}$ scores, whereas the highest number of page views originated from New York for the HAS-BLED score and Washington for the MAP score. Use patterns for the NIHSS calculator are shown in Table 2, which shows similar use patterns as for the $\mathrm{CHA}_{2} \mathrm{DS}_{2}$-VASc, HAS-BLED, and $\mathrm{CHADS}_{2}$ score calculators. The MAP calculator use pattern is represented separately in Table 3.

Table 2. Growth in relative page views of the National Institutes of Health Stroke Scale score calculator by quarter and year.

\begin{tabular}{ll}
\hline Quarter (year) & Proportion of total page views, \% \\
\hline Q1 (2016) & 4.2 \\
Q2 (2016) & 4.3 \\
Q3 (2016) & 6.6 \\
Q4 (2016) & 4.7 \\
Q1 (2017) & 6.7 \\
Q2 (2017) & 6.5 \\
Q3 (2017) & 7 \\
Q4 (2017) & 8.8 \\
Q1 (2018) & 10.8 \\
Q2 (2018) & 12.2 \\
Q3 (2018) & 13.9 \\
Q4 (2018) & 14.2 \\
\hline
\end{tabular}

Table 3. Growth in relative page views of the Mean Arterial Pressure score calculator by quarter and year.

\begin{tabular}{ll}
\hline Quarter (year) & Proportion of total page views, \% \\
\hline Q1 (2016) & 5.1 \\
Q2 (2016) & 5.4 \\
Q3 (2016) & 8.5 \\
Q4 (2016) & 7 \\
Q1 (2017) & 7.2 \\
Q2 (2017) & 7.5 \\
Q3 (2017) & 8 \\
Q4 (2017) & 8.5 \\
Q1 (2018) & 9.9 \\
Q2 (2018) & 10 \\
Q3 (2018) & 10.6 \\
Q4 (2018) & 12 \\
\hline
\end{tabular}

All 5 calculators were predominantly accessed by web browser rather than by mobile apps. The proportion of access attributable to web browsers varied depending on the specific calculator. However, web browser access accounted for $82.7 \%-91.2 \%$ of frequently used stroke calculator page views, with the NIHSS and MAP calculators respectively representing the minimum and maximum in the range. The NIHSS calculator had the highest proportion of Android app page views (10.7\%). Two calculators, the NIHSS and CHA2DS2-VASc, generated the highest and equal proportion of iOS app pageviews (6.6\%) (data not shown). The NIHSS score calculator demonstrated the greatest increase in page views ( $238.1 \%$ increase) between the first and last quarters of the study period (Table 2).

All 5 calculators were released by MDCalc between January 2009 and April 2011. In chronological order, the $\mathrm{CHADS}_{2}$ score 
and MAP calculators were released the earliest (January 1, 2009), followed by the NIHSS calculator (January 1, 2011) and the HAS-BLED and $\mathrm{CHA}_{2} \mathrm{DS}_{2}$-VASc score calculators (April 1, 2011). Over the study period, the $\mathrm{CHA}_{2} \mathrm{DS}_{2}$-VASc score calculator was ranked 2nd; MAP, 7th; HAS-BLED, 9th; NIHSS, 15th' and $\mathrm{CHADS}_{2}, 22 \mathrm{nd}$. By contrast, between January 2011 and December 2016, the corresponding ranks for these calculators were $2 \mathrm{nd}, 31 \mathrm{st}, 12 \mathrm{th}, 33 \mathrm{rd}$, and $7 \mathrm{th}$, respectively (Table 1).

\section{Discussion}

\section{Principal Findings}

In this study, we found that the most frequently accessed calculators relating to stroke comprised 1 of 3 types: risk prediction tools for complications that were conditional on the presence of a specific disease state (eg, $\mathrm{CHADS}_{2}, \mathrm{HAS}-\mathrm{BLED}$, and $\mathrm{CHA}_{2} \mathrm{DS}_{2}$-VASc scores), scales to quantify severity in ischemic stroke (eg, NIHSS), and calculators for computing physiologic parameters (eg, MAP). These calculators were among the most frequently used calculators on the MDCalc platform, as demonstrated by the CHA2DS2-VASc score calculator that ranked second by relative page views in both the 2011-2015 and 2016-2018 periods and by the increases in ranks observed in all stroke calculators during the 2016-2018 period. The majority of the calculators were accessed from the most highly populated US states [30] with the greatest number of licensed physicians [31]. While a number of page views did originate from outside the United States, most of these, nonetheless, originated from English-language countries.

\section{Characteristics of Highly Used Stroke Calculators}

\section{English-Language Dominance and Association With High-Prevalence Conditions}

Many drivers of stroke calculator use that we uncovered in our analysis may also be generalizable features of highly used calculators outside the field of stroke. One primary such driver may be the predominance of the English language, which is best exemplified by our findings that the highest rates of geographical calculator use originated in English-language countries. However, potential additional factors contributing to the predominance of English in calculator use include the widespread use of English in scientific and clinical communities worldwide [32], the fact that MDCalc has an English-only website [29] and was founded by 2 US emergency medicine physicians, and the platform's primarily word-of-mouth advertising strategy in English-language countries. A second potentially generalizable feature of highly used calculators is high disease prevalence. Our findings demonstrate that 3 of the $5(60 \%)$ most highly used calculators related to atrial fibrillation, which is both highly prevalent in elderly patients [33] as well as patients with ischemic stroke [34]. As suggested by our findings, calculators addressing highly prevalent diseases may be likely to generate higher use.

\section{Inclusion in Professional Society Guidelines}

A third potentially generalizable feature of calculators is their inclusion of corresponding scores in professional society guidelines, as shown in our study by both $\mathrm{CHA}_{2} \mathrm{DS}_{2}$-VASc and HAS-BLED. The former score was incorporated into US and international professional society guidelines for the management of atrial fibrillation, including the European Society of Cardiovascular in 2012 and 2016 [35,36], the American Heart Association in 2014 [37], the National Institute for Health and Care Excellence United Kingdom guidelines in 2014 [38], and the Asia Pacific Heart Rhythm Society guidelines in 2017 [39]. Similarly, the HAS-BLED score was incorporated in European Society of Cardiovascular in 2012 and 2016 [35,36], the Canadian Cardiovascular Society in 2014 and 2018 [40,41], and the National Institute for Health and Care Excellence United Kingdom guidelines in 2014 [38]. Relatedly, evidence suggests that the predictive ability of the HAS-BLED score outperformed that of other hemorrhage risk scores [42], which may have also solidified this score's position in multiple society guidelines.

\section{Updates to Widely Used Score Calculators}

A fourth factor associated with high calculator popularity may be the use of calculators for clinical scores that constitute an update to an already existing high-profile clinical score. In our study, this is best exemplified by the $\mathrm{CHA}_{2} \mathrm{DS}_{2}$-VASc score, which was responsible for nearly one-third of stroke-related calculator page views between 2016 and 2018. This score was originally developed as a risk stroke prediction tool in atrial fibrillation that was improved compared with the existing $\mathrm{CHADS}_{2}$ score by incorporating several additional thromboembolic risk factors [17]. Dating back to the original score's publication in Journal of the American Medical Association in 2001, practicing clinicians may have already been familiar with the concept of data-driven stroke risk prediction in atrial fibrillation by the time of the second score's publication in 2009. This familiarity, in turn, may have cemented widespread acceptance of the $\mathrm{CHA}_{2} \mathrm{DS}_{2}$-VASc score's viability as a clinical risk predictor.

\section{Broad Applicability to Nonstroke Conditions}

Applicability of calculators to multiple disease states may be additionally responsible for widespread use. For instance, we found that the second-most used cerebrovascular calculator was the MAP, which rose in relative page views between the 5-year period ending on December 31, 2015 and the end of the 3-year study period. Although MAP is often used to guide management of aneurysmal subarachnoid hemorrhage [43], our findings are likely attributable to the usefulness of MAP in diagnosing and managing several nonstroke states, such as sepsis, septic shock [44], and neurotrauma [45]. Indeed, in addition to subarachnoid hemorrhage, MDCalc metadata tags for the MAP calculator include both "sepsis" and "trauma." Considering that severe sepsis and septic shock have higher yearly incidence than subarachnoid hemorrhage [46,47], the usefulness of MAP in the management of sepsis, rather than subarachnoid hemorrhage, may have been a more likely explanation for the high use of the MAP calculator during the study period. MAP is also less commonly used than systolic and diastolic blood pressure to guide the management of acute ischemic stroke $[48,49]$ and intracerebral hemorrhage [50], thereby further supporting the theory that noncerebrovascular use cases were likely to be the primary drivers of high MAP calculator page views. 


\section{Score Use in High-Profile Randomized Trials}

Inclusion of scores in high-profile randomized trials may also translate to high use of calculators associated with these scores. While the NIHSS score is not the sole factor in selecting patients for tissue plasminogen activator in acute ischemic stroke [49], the NIHSS was included in the first randomized controlled trial of tissue plasminogen activator for acute ischemic stroke [51] and incorporated as an inclusion criterion for several large randomized controlled trials demonstrating the effectiveness of mechanical thrombectomy for acute ischemic stroke due to anterior circulation large-vessel arterial occlusion [52-55], along with several confirmatory meta-analyses in 2015 and 2016 [56,57].

Factors other than guideline adoptions and validations for study publications may also explain the patterns we observed in our study, such as increased global use of medical calculators and increased popularity of the MDCalc service across all calculators. These factors remain difficult to measure. In addition, several health care institutions across the world already use internal calculator repositories for clinical care, which are variably integrated into institutional EHRs. While the worldwide extent of this practice remains poorly characterized, increasing prevalence of such repositories in the future is likely to reduce clinician reliance on and use of external calculators.

\section{Duration of Calculator Availability}

Calculators that are released earlier may also be more widely employed than more recently released calculators due to increased awareness or ongoing search engine optimization. In this study, incorporation into society guidelines may be the main factor explaining why $\mathrm{CHA}_{2} \mathrm{DS}_{2}$-VASc and $\mathrm{HAS}$-BLED calculators were released the latest, yet demonstrated higher use than calculators that were released earlier, such as the MAP, $\mathrm{CHADS}_{2}$ and NIHSS. However, the unmistakable presence of calculators such as the MAP and NIHSS among the 5 most highly used stroke calculators may be a result of their earlier release dates.

\section{Accessibility via Web Browser}

Finally, our findings in stroke calculators suggest that web-accessible calculators may be more widely used than those that are primarily mobile app-based. These results are interesting, given that smartphone ownership in the United States has significantly increased since the early 2010s [58] and smartphone-based and tablet-based calculators are uniquely well suited to clinicians' flexible and dynamic workflow requirements. However, MDCalc's introduction of mobile apps in March 2016 (iOS) [59] and April 2017 (Android) should also be considered when interpreting our results [60]. Moreover, a significant proportion of the predominant web access we observed in our results may have occurred through mobile web browsers, which are highly prevalent in mobile devices and function identically to those found in stationary (eg, laptop or desktop) computers. However, because this study could not differentiate these different types of web access or the context in which these calculators were used, our findings cannot allow us to make definitive conclusions regarding the optimal mode or setting for stroke calculator deployment.

\section{Limitations}

This study was limited by several factors. First, we restricted our analysis to calculators from a single platform. Because many other web-based CDS platforms are available for use, our results may not generalize to other platforms or to the entire community of medical professionals that actively use the 5 identified stroke-related scores in day-to-day practice. Second, because we used deidentified page view data for the study, we lacked user information that could permit a more detailed understanding of calculator use, such as discipline, medical speciality, level of training, as well as EHR, care setting, and disease states in which stroke-related calculators were used. For similar reasons, we have limited insight into whether MDCalc calculator use was potentially affected by alternative calculators embedded in care providers' EHRs. Third, we did not investigate the effects these calculators, as CDS tools, had on aspects of clinician decision-making, such as diagnostic speed and accuracy, as studied by Abedin and colleagues [61]. We also did not investigate the relationship between calculator use and adherence to best practices or meaningful clinical outcomes. Finally, our study period was restricted to 3 years, which may have provided limited insights on use patterns and impacts on clinical care, especially as smartphone and mobile app usage have only become more ubiquitous since 2018 .

\section{Conclusions}

In this retrospective analysis, we demonstrated that the most commonly used stroke calculators were related to secondary stroke prevention in atrial fibrillation, blood pressure measurement, and computation of the NIHSS score. As medical calculators become increasingly important CDS tools, further studies should seek to understand optimal implementation and integration of these calculators into EHR systems and clinical care pathways. This can be achieved by incorporating a broader spectrum of calculator platforms, including platforms for user specialty and training and analyses of the behavior of clinicians during calculator use at the point of care. Additionally, considering our findings that stroke calculators were predominantly adopted in English-speaking countries and highly populated areas, further studies should aim to investigate barriers to adoption and whether translation of calculators into non-English languages may potentially improve calculator adoption.

\section{Authors' Contributions}

BK conceptualized the study, drafted the manuscript, analyzed and interpreted study data, and revised the manuscript for intellectual content. LS obtained and analyzed data and revised the manuscript for intellectual content. RK conceptualized the study, obtained and analyzed data, and revised the manuscript for intellectual content. JH analyzed data and revised the manuscript for intellectual content. NJ revised the manuscript for intellectual content. 


\section{Conflicts of Interest}

JH is the cofounder and owner of MD Aware LLC. LS is a full-time employee of MD Aware LLC. RK is a full-time of employee of Ro. BK serves on the advisory board of and owns equity in Syntrillo LLC. NJ is the Bludhorn Professor of International Medicine at the Icahn School of Medicine at Mount Sinai. She receives grant funding paid to her institution for grants unrelated to this work from NINDS (NIH U24NS107201, NIH IU54NS100064) and PCORI. She receives an honorarium for her work as an Associate Editor of Epilepsia.

\section{Multimedia Appendix 1}

Example of an MDCalc medical calculator webpage $(\mathrm{CHA}<\mathrm{sub}>2</$ sub $>$ DS $<$ sub $>2</$ sub $>$-VASc Score for Atrial Fibrillation Stroke Risk).

[PNG File, 76 KB-Multimedia Appendix 1]

\section{References}

1. Gold M, Mc L. Assessing HITECH Implementation and Lessons: 5 Years Later. Milbank Q 2016 Sep;94(3):654-687 [FREE Full text] [doi: 10.1111/1468-0009.12214] [Medline: 27620687]

2. Adler-Milstein J, Holmgren A, Kralovec P, Worzala C, Searcy T, Patel V. Electronic health record adoption in US hospitals: the emergence of a digital "advanced use" divide. J Am Med Inform Assoc 2017 Nov 01;24(6):1142-1148 [FREE Full text] [doi: 10.1093/jamia/ocx080] [Medline: 29016973]

3. Farri O, Pieckiewicz D, Rahman A, Adam T, Pakhomov S, Melton G. A qualitative analysis of ehr clinical document synthesis by clinicians. 2012 Presented at: Proceedings of the American Medical Informatics Association Annual Symposium; . PMC3540510; 2012; Chicago, Illinois.

4. Pivovarov R, Elhadad N. Automated methods for the summarization of electronic health records. J Am Med Inform Assoc 2015 Sep;22(5):938-947 [FREE Full text] [doi: 10.1093/jamia/ocv032] [Medline: 25882031]

5. Aakre C, Dziadzko M, Keegan M, Herasevich V. Automating Clinical Score Calculation within the Electronic Health Record. Appl Clin Inform 2017 Dec 21;08(02):369-380. [doi: 10.4338/aci-2016-09-ra-0149]

6. Dorner S, Yun B, Kwon R, Habboushe J, Raja A. Characteristics of frequently used clinical decision support tools. Physician Leadership Journal 2018 Nov 11;5(6):62-66.

7. Bubp J, Park M, Kapusnik-Uner J, Dang T, Matuszewski K, Ly D, et al. Successful deployment of drug-disease interaction clinical decision support across multiple Kaiser Permanente regions. J Am Med Inform Assoc 2019 Oct 01;26(10):905-910 [FREE Full text] [doi: 10.1093/jamia/ocz020] [Medline: 30986823]

8. Devarakonda MV, Mehta N, Tsou C, Liang JJ, Nowacki AS, Jelovsek JE. Automated problem list generation and physicians perspective from a pilot study. Int J Med Inform 2017 Sep;105:121-129 [FREE Full text] [doi:

10.1016/j.ijmedinf.2017.05.015] [Medline: 28750905]

9. Habboushe J, Altman C, Lip GYH. Time trends in use of the CHADS and CHA DS VASc scores, and the geographical and specialty uptake of these scores from a popular online clinical decision tool and medical reference. Int J Clin Pract 2019 Feb 30;73(2):e13280. [doi: 10.1111/ijcp.13280] [Medline: 30281876]

10. Green T, Whitt S, Belden J, Erdelez S, Shyu C. Medical calculators: Prevalence, and barriers to use. Comput Methods Programs Biomed 2019 Oct;179:105002 [FREE Full text] [doi: 10.1016/j.cmpb.2019.105002] [Medline: 31443857]

11. Green T, Shyu C. Developing a Taxonomy of Online Medical Calculators for Assessing Automatability and Clinical Efficiency Improvements. Stud Health Technol Inform 2019 Aug 21;264:601-605. [doi: 10.3233/SHTI190293] [Medline: 31437994]

12. Tong X, Yang Q, Ritchey MD, George MG, Jackson SL, Gillespie C, et al. The Burden of Cerebrovascular Disease in the United States. Prev Chronic Dis 2019 Apr 25;16:180411 [FREE Full text] [doi: 10.5888/pcd16.180411] [Medline: 31022369]

13. Feigin V, Krishnamurthi R, Parmar P, Norrving B, Mensah GA, Bennett DA, et al. Update on the Global Burden of Ischemic and Hemorrhagic Stroke in 1990-2013: The GBD 2013 Study. Neuroepidemiology 2015;45(3):161-176 [FREE Full text] [doi: 10.1159/000441085] [Medline: 26505981]

14. Flint A, Cullen S, Faigeles B, Rao V. Predicting long-term outcome after endovascular stroke treatment: the totaled health risks in vascular events score. AJNR Am J Neuroradiol 2010 Aug;31(7):1192-1196 [FREE Full text] [doi:

10.3174/ajnr.A2050] [Medline: 20223889]

15. Ntaios G, Faouzi M, Ferrari J, Lang W, Vemmos K, Michel P. An integer-based score to predict functional outcome in acute ischemic stroke: the ASTRAL score. Neurology 2012 Jun 12;78(24):1916-1922. [doi: 10.1212/WNL.0b013e318259e221] [Medline: 22649218]

16. Singer D, Chang Y, Borowsky L, Fang MC, Pomernacki NK, Udaltsova N, et al. A new risk scheme to predict ischemic stroke and other thromboembolism in atrial fibrillation: the ATRIA study stroke risk score. J Am Heart Assoc 2013 Jun 21;2(3):e000250 [FREE Full text] [doi: 10.1161/JAHA.113.000250] [Medline: 23782923]

17. Lip GYH, Nieuwlaat R, Pisters R, Lane DA, Crijns HJGM. Refining clinical risk stratification for predicting stroke and thromboembolism in atrial fibrillation using a novel risk factor-based approach: the euro heart survey on atrial fibrillation. Chest 2010 Feb;137(2):263-272. [doi: 10.1378/chest.09-1584] [Medline: 19762550] 
18. Gage B, Waterman A, Shannon W, Boechler M, Rich M, Radford M. Validation of clinical classification schemes for predicting stroke: results from the National Registry of Atrial Fibrillation. JAMA 2001 Jun 13;285(22):2864-2870. [doi: 10.1001/jama.285.22.2864] [Medline: 11401607]

19. Fisher CM, Kistler JP, Davis JM. Relation of cerebral vasospasm to subarachnoid hemorrhage visualized by computerized tomographic scanning. Neurosurgery 1980 Jan;6(1):1-9. [doi: 10.1227/00006123-198001000-00001] [Medline: 7354892]

20. Johnston SC, Rothwell PM, Nguyen-Huynh MN, Giles MF, Elkins JS, Bernstein AL, et al. Validation and refinement of scores to predict very early stroke risk after transient ischaemic attack. The Lancet 2007 Jan;369(9558):283-292. [doi: 10.1016/s0140-6736(07)60150-0]

21. Hemphill J, Bonovich DC, Besmertis L, Manley GT, Johnston SC. The ICH score: a simple, reliable grading scale for intracerebral hemorrhage. Stroke 2001 Apr;32(4):891-897. [doi: 10.1161/01.str.32.4.891] [Medline: 11283388]

22. Delgado Almandoz JE, Schaefer P, Goldstein J, Rosand J, Lev MH, González RG, et al. Practical scoring system for the identification of patients with intracerebral hemorrhage at highest risk of harboring an underlying vascular etiology: the Secondary Intracerebral Hemorrhage Score. AJNR Am J Neuroradiol 2010 Oct;31(9):1653-1660 [FREE Full text] [doi: 10.3174/ajnr.A2156] [Medline: 20581068]

23. Strbian D, Engelter S, Michel P, Meretoja A, Sekoranja L, Ahlhelm FJ, et al. Symptomatic intracranial hemorrhage after stroke thrombolysis: the SEDAN score. Ann Neurol 2012 May;71(5):634-641. [doi: 10.1002/ana.23546] [Medline: 22522478]

24. Myint PK, Clark AB, Kwok CS, Davis J, Durairaj R, Dixit AK, et al. The SOAR (Stroke subtype, Oxford Community Stroke Project classification, Age, prestroke modified Rankin) score strongly predicts early outcomes in acute stroke. Int J Stroke 2014 Apr 09;9(3):278-283. [doi: 10.1111/ijs.12088] [Medline: 23834262]

25. Pisters R, Lane DA, Nieuwlaat R, de Vos CB, Crijns HJGM, Lip GYH. A novel user-friendly score (HAS-BLED) to assess 1-year risk of major bleeding in patients with atrial fibrillation: the Euro Heart Survey. Chest 2010 Nov;138(5):1093-1100. [doi: 10.1378/chest.10-0134] [Medline: 20299623]

26. Hunt W, Hess R. Surgical risk as related to time of intervention in the repair of intracranial aneurysms. J Neurosurg 1968 Jan;28(1):14-20. [doi: 10.3171/jns.1968.28.1.0014] [Medline: 5635959]

27. Kernan WN, Ovbiagele B, Black HR, Bravata DM, Chimowitz MI, Ezekowitz MD, et al. Guidelines for the prevention of stroke in patients with stroke and transient ischemic attack: a guideline for healthcare professionals from the American Heart Association/American Stroke Association. Stroke 2014 Jul;45(7):2160-2236. [doi: 10.1161/STR.0000000000000024] [Medline: 24788967]

28. American Heart Association. Secondary stroke prevention checklist. Secondary stroke prevention checklist. 2019. URL: https://www.stroke.org/-/media/stroke-files/stroke-resource-center/recovery/patient-focused/ secondary-stroke-prevention-checklist.pdf?la=en [accessed 2020-08-05]

29. MDCalc. MDCalc - Medical calculators, equations, scores, and guidelines. MDCalc website. 2019. URL: https://www. mdcalc.com [accessed 2019-09-14]

30. United States Census Bureau, Population Division. Annual Estimates of the Resident Population for the United States, Regions, States, and Puerto Rico: April 1, 2010 to July 1, 2018 (nst-est2018-01). United States Census 2018 National and State Population Estimates. 2019. URL: http://www2.census.gov/programs-surveys/popest/tables/2010-2018/national/totals/ na-est2018-01.xlsx [accessed 2019-11-19]

31. Young A, Chaudhry H, Pei X, Arnhart K, Dugan M, Steingard S. Federation of State Medical Boards Census of licensed physicians in the united states, 2018. J Med Reg 2019;105(2):7-23 [FREE Full text] [doi: 10.30770/2572-1852-105.2.7]

32. Roca A, Boum Y, Wachsmuth I. Plaidoyer contre l'exclusion des francophones dans la recherche en santé mondiale. The Lancet Global Health 2019 Jun;7(6):e701-e702. [doi: 10.1016/s2214-109x(19)30175-5]

33. Go A, Hylek E, Phillips K, Chang Y, Henault LE, Selby JV, et al. Prevalence of diagnosed atrial fibrillation in adults: national implications for rhythm management and stroke prevention: the AnTicoagulation and Risk Factors in Atrial Fibrillation (ATRIA) Study. JAMA 2001 May 09;285(18):2370-2375. [doi: 10.1001/jama.285.18.2370] [Medline: 11343485]

34. Wolf PA, Abbott RD, Kannel WB. Atrial fibrillation as an independent risk factor for stroke: the Framingham Study. Stroke 1991 Aug;22(8):983-988. [doi: 10.1161/01.str.22.8.983] [Medline: 1866765]

35. Camm A, Lip G, De Caterina R, Savelieva I, Atar D, Hohnloser SH, et al. 2012 focused update of the ESC Guidelines for the management of atrial fibrillation: an update of the 2010 ESC Guidelines for the management of atrial fibrillation. Developed with the special contribution of the European Heart Rhythm Association. Eur Heart J 2012 Nov;33(21):2719-2747. [Medline: 22922413]

36. Kirchhof P, Benussi S, Kotecha D, Ahlsson A, Atar D, Casadei B, et al. 2016 ESC Guidelines for the management of atrial fibrillation developed in collaboration with EACTS. Eur Heart J 2016 Oct 07;37(38):2893-2962. [doi: 10.1093/eurheartj/ehw210] [Medline: 27567408]

37. January CT, Wann LS, Alpert JS, Calkins H, Cigarroa JE, Cleveland JC, American College of Cardiology/American Heart Association Task Force on Practice Guidelines. 2014 AHA/ACC/HRS guideline for the management of patients with atrial fibrillation: a report of the American College of Cardiology/American Heart Association Task Force on Practice Guidelines and the Heart Rhythm Society. J Am Coll Cardiol 2014 Dec 02;64(21):e1-76 [FREE Full text] [doi: 10.1016/j.jacc.2014.03.022] [Medline: 24685669] 
38. Jones C, Pollit V, Fitzmaurice D, Cowan C, Guideline Development Group. The management of atrial fibrillation: summary of updated NICE guidance. BMJ 2014 Jun 19;348:g3655. [doi: 10.1136/bmj.g3655] [Medline: 24948694]

39. Chiang C, Okumura K, Zhang S, Chao T, Siu C, Wei Lim T, et al. 2017 consensus of the Asia Pacific Heart Rhythm Society on stroke prevention in atrial fibrillation. J Arrhythm 2017 Aug;33(4):345-367 [FREE Full text] [doi: 10.1016/j.joa.2017.05.004] [Medline: 28765771]

40. Verma A, Cairns JA, Mitchell LB, Macle L, Stiell IG, Gladstone D, CCS Atrial Fibrillation Guidelines Committee. 2014 focused update of the Canadian Cardiovascular Society Guidelines for the Management of atrial fibrillation. Can J Cardiol 2014 Oct;30(10):1114-1130. [doi: 10.1016/j.cjca.2014.08.001] [Medline: 25262857]

41. Andrade JG, Verma A, Mitchell LB, Parkash R, Leblanc K, Atzema C, et al. 2018 Focused Update of the Canadian Cardiovascular Society Guidelines for the Management of Atrial Fibrillation. Can J Cardiol 2018 Nov;34(11):1371-1392. [doi: 10.1016/j.cjca.2018.08.026] [Medline: 30404743]

42. Apostolakis S, Lane D, Guo Y, Buller H, Lip G. Performance of the HEMORR(2)HAGES, ATRIA, and HAS-BLED bleeding risk-prediction scores in patients with atrial fibrillation undergoing anticoagulation: the AMADEUS (evaluating the use of SR34006 compared to warfarin or acenocoumarol in patients with atrial fibrillation) study. J Am Coll Cardiol 2012 Aug 28;60(9):861-867 [FREE Full text] [doi: 10.1016/j.jacc.2012.06.019] [Medline: 22858389]

43. Diringer M, Bleck T, Claude Hemphill J, Menon D, Shutter L, Vespa P, et al. Critical care management of patients following aneurysmal subarachnoid hemorrhage: recommendations from the Neurocritical Care Society's Multidisciplinary Consensus Conference. Neurocrit Care 2011 Sep;15(2):211-240. [doi: 10.1007/s12028-011-9605-9] [Medline: 21773873]

44. Dellinger RP, Levy MM, Rhodes A, Annane D, Gerlach H, Opal SM, Surviving Sepsis Campaign Guidelines Committee including the Pediatric Subgroup. Surviving sepsis campaign: international guidelines for management of severe sepsis and septic shock: 2012. Crit Care Med 2013 Feb;41(2):580-637. [doi: 10.1097/CCM.0b013e31827e83af] [Medline: 23353941]

45. Long B, Koyfman A. Secondary Gains: Advances in Neurotrauma Management. Emerg Med Clin North Am 2018 Feb;36(1):107-133. [doi: 10.1016/j.emc.2017.08.007] [Medline: 29132572]

46. Mouncey PR, Osborn TM, Power GS, Harrison DA, Sadique MZ, Grieve RD, et al. Trial of Early, Goal-Directed Resuscitation for Septic Shock. N Engl J Med 2015 Apr 02;372(14):1301-1311. [doi: 10.1056/nejmoa1500896]

47. de Rooij NK, Linn F, van der Plas JA, Algra A, Rinkel G. Incidence of subarachnoid haemorrhage: a systematic review with emphasis on region, age, gender and time trends. J Neurol Neurosurg Psychiatry 2007 Dec;78(12):1365-1372 [FREE Full text] [doi: 10.1136/jnnp.2007.117655] [Medline: 17470467]

48. Powers WJ, Rabinstein AA, Ackerson T, Adeoye OM, Bambakidis NC, Becker K, et al. 2018 Guidelines for the Early Management of Patients With Acute Ischemic Stroke: A Guideline for Healthcare Professionals From the American Heart Association/American Stroke Association. Stroke 2018 Mar;49(3):e46-e110. [doi: 10.1161/STR.0000000000000158] [Medline: 29367334]

49. Jauch EC, Saver JL, Adams HP, Bruno A, Connors JJB, Demaerschalk BM, et al. Guidelines for the early management of patients with acute ischemic stroke: a guideline for healthcare professionals from the American Heart Association/American Stroke Association. Stroke 2013 Mar;44(3):870-947 [FREE Full text] [doi: 10.1161/STR.0b013e318284056a] [Medline: 23370205]

50. Hemphill JC, Greenberg SM, Anderson CS, Becker K, Bendok BR, Cushman M, et al. Guidelines for the Management of Spontaneous Intracerebral Hemorrhage. Stroke 2015 May 28;46(7):2032-2060. [doi: 10.1161/str.0000000000000069]

51. National Institute of Neurological DisordersStroke rt-PA Stroke Study Group. Tissue plasminogen activator for acute ischemic stroke. N Engl J Med 1995 Dec 14;333(24):1581-1587. [doi: 10.1056/NEJM199512143332401] [Medline: 7477192]

52. Berkhemer OA, Fransen PS, Beumer D, van den Berg LA, Lingsma HF, Yoo AJ, et al. A randomized trial of intraarterial treatment for acute ischemic stroke. N Engl J Med 2015 Jan 01;372(1):11-20. [doi: 10.1056/NEJMoa1411587] [Medline: 25517348]

53. Campbell BCV, Mitchell PJ, Kleinig TJ, Dewey HM, Churilov L, Yassi N, et al. Endovascular therapy for ischemic stroke with perfusion-imaging selection. N Engl J Med 2015 Mar 12;372(11):1009-1018. [doi: 10.1056/NEJMoa1414792] [Medline: 25671797]

54. Molina C, Chamorro A, Rovira A, de Miquel A, Serena J, Roman LS, et al. REVASCAT: a randomized trial of revascularization with SOLITAIRE FR device vs. best medical therapy in the treatment of acute stroke due to anterior circulation large vessel occlusion presenting within eight-hours of symptom onset. Int J Stroke 2015 Jun;10(4):619-626. [doi: 10.1111/ijs.12157] [Medline: 24206399]

55. Saver JL, Goyal M, Bonafe A, Diener H, Levy EI, Pereira VM, et al. Stent-retriever thrombectomy after intravenous t-PA vs. t-PA alone in stroke. N Engl J Med 2015 Jun 11;372(24):2285-2295. [doi: 10.1056/NEJMoa1415061] [Medline: 25882376]

56. Badhiwala J, Nassiri F, Alhazzani W, Selim MH, Farrokhyar F, Spears J, et al. Endovascular Thrombectomy for Acute Ischemic Stroke: A Meta-analysis. JAMA 2015 Nov 03;314(17):1832-1843. [doi: 10.1001/jama.2015.13767] [Medline: 26529161] 
57. Goyal M, Menon BK, van Zwam WH, Dippel DWJ, Mitchell PJ, Demchuk AM, et al. Endovascular thrombectomy after large-vessel ischaemic stroke: a meta-analysis of individual patient data from five randomised trials. Lancet 2016 Apr 23;387(10029):1723-1731. [doi: 10.1016/S0140-6736(16)00163-X] [Medline: 26898852]

58. Demographics of mobile phone ownership and adoption in the united states. Pew Research Center Mobile Fact Sheet. 2019. URL: https://www.pewresearch.org/internet/fact-sheet/mobile/ [accessed 2020-09-21]

59. Maurer D. MDCalc app, the best online medical calculator, is now an app. iMedicalApps. URL: https://www. imedicalapps.com/2016/03/mdcalc-medical-calculator-app/ [accessed 2021-02-15]

60. Husain I. MDCalc is finally available for Android. MD Tech Tips. URL: https://www.imedicalapps.com/2017/04/ md-tech-tips-mdcalc/ [accessed 2021-02-15]

61. Abedin Z, Hoerner R, Kawamoto K. Evaluation of a FHIR-based Clinical Decision Support Tool for Calculating CHA2Ds2-VAsc scores. In: Proceedings of the Circulation Cardiovascular Quality and Outcomes Scientific Sessions. Dallas, Texas: American heart Association; 2019 Presented at: Cardiovascular Quality and Outcomes Scientific Sessions; 2019; Arlington, Virginia p. 5-6.

\title{
Abbreviations
}

CDS: clinical decision support.

CHADS $_{2}$ : congestive heart failure, hypertension, 75 years of age or older, diabetes mellitus, and previous stroke or transient ischemic attack.

CHA $_{2}$ DS $_{2}$-VASc: congestive heart failure, hypertension, 75 years of age and older, diabetes mellitus, previous stroke or transient ischemic attack, vascular disease, 65 to 74 years of age, female.

EHR: electronic health record.

HAS-BLED: hypertension, abnormal renal/liver function, stroke, bleeding history or predisposition, labile international normalized ratio, elderly, drugs/alcohol concomitantly.

MAP: mean arterial pressure.

NIHSS: National Institutes of Health Stroke Scale.

\author{
Edited by C Lovis; submitted 10.03.21; peer-reviewed by A Nowacki, L Chirchir; comments to author 14.04.21; revised version \\ received 24.05.21; accepted 05.06.21; published 02.08.21 \\ Please cite as: \\ Kummer B, Shakir L, Kwon R, Habboushe J, Jetté N \\ Usage Patterns of Web-Based Stroke Calculators in Clinical Decision Support: Retrospective Analysis \\ JMIR Med Inform 2021;9(8):e28266 \\ URL: https://medinform.jmir.org/2021/8/e28266 \\ doi: $10.2196 / 28266$ \\ PMID: $\underline{34338647}$
}

CBenjamin Kummer, Lubaina Shakir, Rachel Kwon, Joseph Habboushe, Nathalie Jetté. Originally published in JMIR Medical Informatics (https://medinform.jmir.org), 02.08.2021. This is an open-access article distributed under the terms of the Creative Commons Attribution License (https://creativecommons.org/licenses/by/4.0/), which permits unrestricted use, distribution, and reproduction in any medium, provided the original work, first published in JMIR Medical Informatics, is properly cited. The complete bibliographic information, a link to the original publication on https://medinform.jmir.org/, as well as this copyright and license information must be included. 